\title{
P0197
}

\section{THE RESPONSES OF THE AUTONOMIC NERVOUS SYSTEM ON HUMANS WHEN WORKING WITH DIFFERENT LED LIGHTING CONDITIONS}

\author{
C.Y. Chen et al. \\ DOI 10.25039/x46.2019.PO197 \\ from \\ CIE x046:2019 \\ Proceedings \\ of the \\ 29th CIE SESSION \\ Washington D.C., USA, June 14 - 22, 2019 \\ (DOI 10.25039/x46.2019)
}

The paper has been presented at the 29th CIE Session, Washington D.C., USA, June 14-22, 2019. It has not been peer-reviewed by CIE.

(C) CIE 2019

All rights reserved. Unless otherwise specified, no part of this publication may be reproduced or utilized in any form or by any means, electronic or mechanical, including photocopying and microfilm, without permission in writing from CIE Central Bureau at the address below. Any mention of organizations or products does not imply endorsement by the CIE.

This paper is made available open access for individual use. However, in all other cases all rights are reserved unless explicit permission is sought from and given by the CIE.

CIE Central Bureau

Babenbergerstrasse 9

A-1010 Vienna

Austria

Tel.: +43 17143187

e-mail: ciecb@cie.co.at

www.cie.co.at 


\title{
THE RESPONSES OF THE AUTONOMIC NERVOUS SYSTEM ON HUMANS WHEN WORKING WITH DIFFERENT LED LIGHTING CONDITIONS
}

\author{
Chen, C.Y. ${ }^{1}$, Luo, M.R. ${ }^{1}$, Wu, P.J. ${ }^{2}$, Tseng, C.Y. ${ }^{3}$, Lin, B.S. ${ }^{3}$, Hou, H.Y. ${ }^{2}$, Chen, C.T. ${ }^{2}$, Tai, W.S. ${ }^{2}$ \\ ${ }^{1}$ Graduate Institute of Colour \& Illumination Technology, National Taiwan University of \\ Science and Technology, Taipei, CHINESE TAIPEI \\ ${ }^{2}$ College of Information and Distribution Science, National Taichung University of Science \\ and Technology, Taichung, CHINESE TAIPEI \\ ${ }^{3}$ Institute of Imaging and Biomedical Photonics, National Chiao Tung University, Tainan, \\ CHINESE TAIPEI \\ pjwu@nutc.edu.tw
}

DOI 10.25039/x46.2019.PO197

\begin{abstract}
Good working luminous environment is primary for interior workers. In this study, human responses of autonomic nervous system to different white LED lighting work environment are proposed, expecting to find out the interior working light source being able to effectively enhance concentration and comfort. Total 12 subjects participated in this experiment. The subjects executed reading and tasks for about 1 hour, when the electrocardiograph signals were fully measured in the experimental process. The electrocardiograph information can be transferred into heart rate variability (HRV), where the high frequency power (HFP) stands for the parasympathestic activity index in human autonomic nervous system and low frequency power (LFP) represents the sympathestic activity index. The experimental results reveal that the subjects obviously enhance the sympathestic activity index under colour temperature $6000 \mathrm{~K}$ and dominant wavelength $420 \mathrm{~nm}$. It shows that the subjects might feel energetic and enhance the concentration under such luminous environment.
\end{abstract}

Keywords: heart rate variability, parasympathestic activity index, sympathestic activity index, LED lighting work environment, concentration

\section{Introduction}

Long working hours is common in the busy and changeable environment. Some studies find the long working hours and high use of eyes would have physical and mental conditions be in longterm fatigue and further increase the risks of emotion, sleep problems, and low work efficiency (Dembe, A. E. et al., 2005), (Cheng, Y. et al., 200). Therefore, good working lighting environment is primary for interior workers. How to improve the office workers' state is the most important issue.

LED is generally used as the lighting source for interior illumination. Thus, we design an experiment to discuss the physiological variation of the autonomic nervous system in different white LED lighting work environment and expect to find out the interior working light source being able to effectively enhance concentration and comfort.

\section{Materials and Methods}

\subsection{Experimental Design}

An experimental space including an tunable lighting system (LEDCube, THOUSLITE), an office desk and a chair was set up as a normal working space with the room temperature $25 \pm 2$ 。C (Bruce-low, S.S. et al., 2006), shown as Figure1. The colour temperature, illumination and the peak wavelength of blue light can be adjusted in this study. The details of lighting conditions were shown as Table1. The adjustable lighting system can achieve the different lighting conditions and the color rendering index of all lights were over $95 \%$ in this study. 

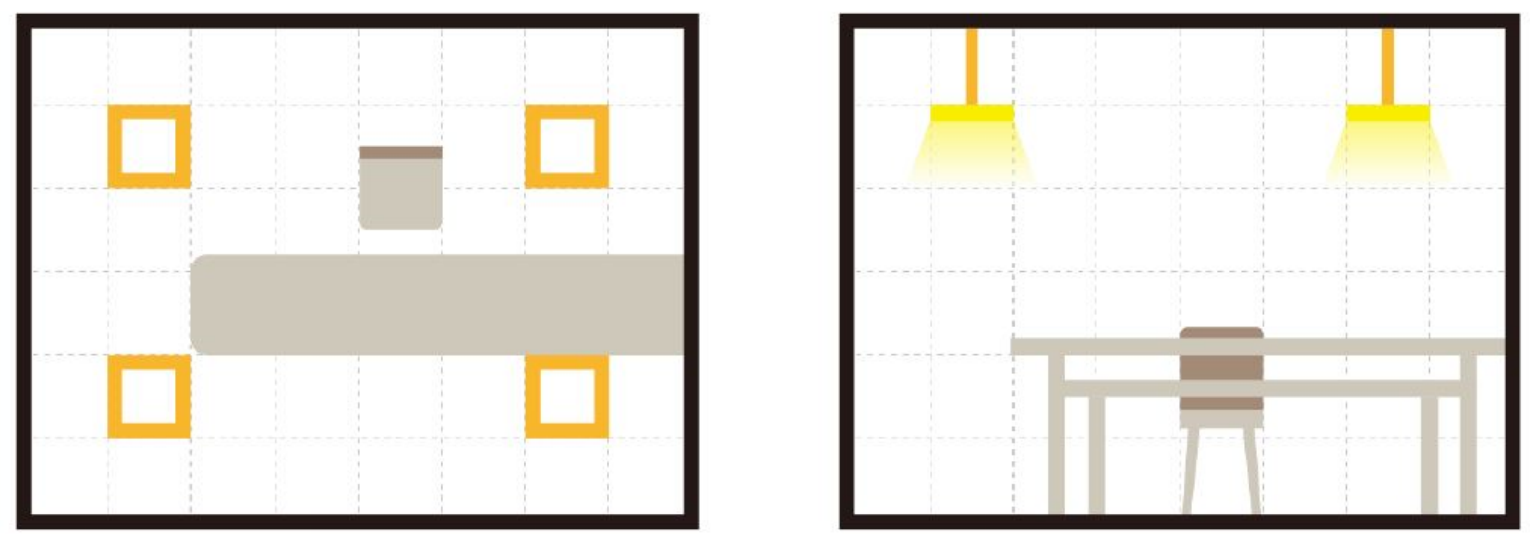

Figure 1 - The Experimental Space

Table 1 - Lighting Conditions

\begin{tabular}{|l|l|}
\hline colour temperature & $4000 \mathrm{~K}, 6000 \mathrm{~K}$ \\
\hline Illumination on the desk & $400 \mathrm{lux}, 700 \mathrm{lux}$ \\
\hline peak wavelength of blue light & $420 \mathrm{~nm}, 460 \mathrm{~nm}, 480 \mathrm{~nm}$ \\
\hline
\end{tabular}

The process in this experiment was shown as Figure2. The total experimental time was about 95 minutes. In the beginning, subjects were in the dark adaptation for 15 minutes to rest. Their electrocardiograph(ECG) signal was detected after dark adaptation. Subjects took a rest for 20 minutes. Then, they did the experimental task for 1 hour. The experimental tasks were including reading, operating task, and proofreading. The ECG signal was detected from rest time to the end of experimental task.

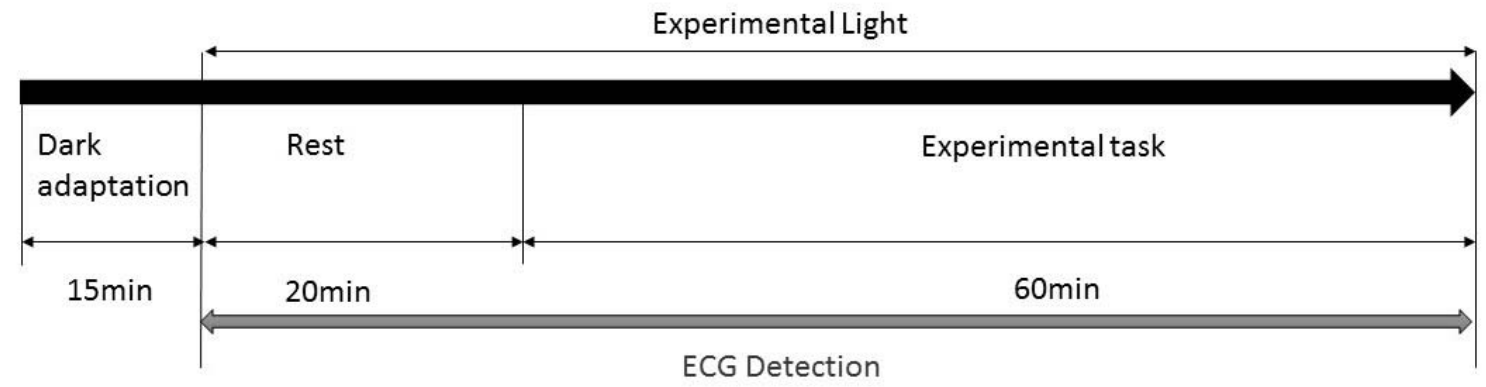

Figure 2 - The Experimental Process

12 healthy volunteers including 6 females and 6 males participated in this study. Their average age was $23.7 \pm 0.6$ years old. For affecting the HRV parameters less, subjects cannot have alcoholism or drug abuse. In addition, they cannot receive medical treatments for any cardiovascular diseases (Akselrod, S. et al.,1987). During the experiment, once the subject felt uncomfortable, such as breathing difficulty, paleness, dizziness or faint, or wishing to stop the experiment, the experiment would be stopped.

All subjects did the experiments at the same time period (from 1:30 p.m. to 5:00 p.m.) during a day for reducing the affection of activity on HRV stability. Each subject merely preceded one experiment in one day that all experiments were randomly completed for 12 days.

\subsection{Analysis of Heart Rate Variability}

In this study, all subjects were taken the ECG measurement while doing the experimental tasks. Biopac MP150 (model ECG 100C, AcqKnowl-edge; Biopac Systems, Santa Barbara, CA, USA) was applied to detect the ECG signal by chest Lead II, shown as Figure3. 


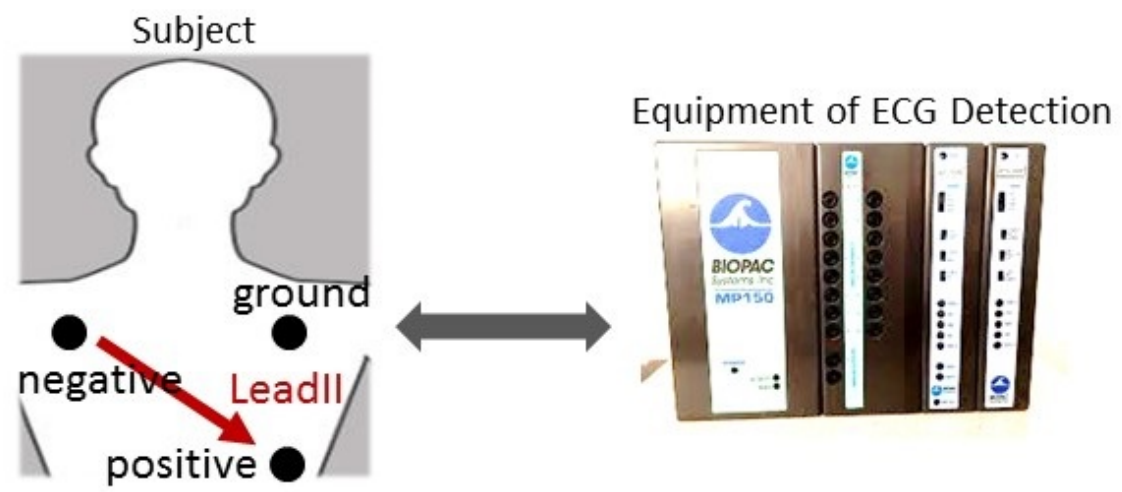

Figure 3 - The Experimental Process

After obtaining the ECG signals from the subjects, the heart rate variability(HRV) analysis can be carried out. Heart rate variability is a way to measure the changes of people's heart beat from the ECG signals. In this study, the measured data is analyzed by using Fourier transform to receive the frequency-domain data to understand the sympathetic and parasympathetic activity changes in human's autonomic nervous system. The parameters of low frequency power (LFP) is power spectral density from $0.04 \mathrm{~Hz}$ to $0.15 \mathrm{~Hz}$. It can be as sympathetic activity. On the other hand, the parameters of high frequency power (HFP) is power spectral density from $0.15 \mathrm{~Hz}$ to $0.4 \mathrm{~Hz}$. It can be as parasympathetic activity (Malik, M. et al., 1996). According the reports (Jorna, P. G., 1992), (Yu, X. et al., 2009), when the activity of sympathetic nervous system is increased, their concentration is also increased. When the activity of parasympathetic nervous system is increased, people feel more relaxed.

\section{Results and Discussion}

According to the report from the European Society of Cardiology and the North American Society of Pacing and Electrophysiology (Malik, M. et al., 1996), LFP is as the sympathetic activity index and HFP is as the parasympathetic activity index. The representation of both indexes can be the two branches of the autonomic nervous system. Therefore, we analyze the variation of HFP and LFP for understanding how the autonomic nervous system changed when people in different lighting conditions.

In Figure 4(a), the value of HFP in group $6000 \mathrm{~K}$ is higher than in group $4000 \mathrm{~K}$ with significance. It shows people might feel more relaxed when doing the experimental tasks with the higher colour temperature. In Figure 4(b), the values of LFP in group 400lux and group 700lux are without much difference. In Figure 4(c), the value of LFP in group 420nm is higher than group $480 \mathrm{~nm}$. It indicates people might have higher concentration during the tasks with the peak wavelength $420 \mathrm{~nm}$.

(a)

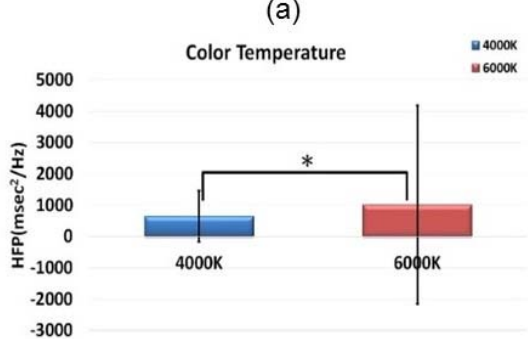

(b)

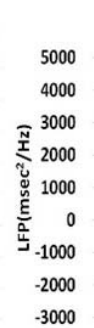

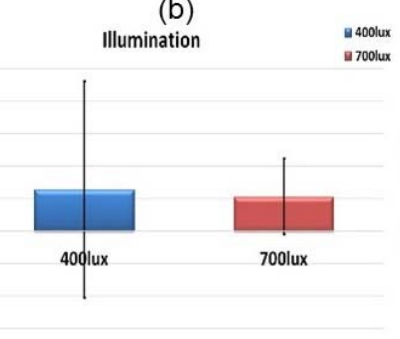

(c)

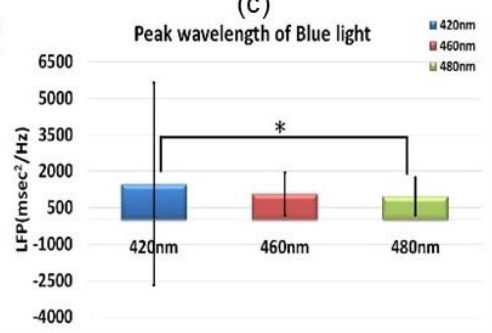

Figure 4- The Responses of Autonomic Nervous System in different (a)colour temperatures (b)illumination (c)peak wavelengths of blue light 


\section{Conclusion}

To sum up the results of this experiment, it indicates staying in the lighting condition with higher colour temperature and $420 \mathrm{~nm}$ peak wavelength of blue light could help people pay more attention during the experimental tasks.

In this study, we use HRV analysis to discuss the responses of the autonomic nervous system in different lighting conditions. It's a non-invasive and useful method to obtain the variation of the autonomic nervous system on human. In the future, the impact of circadian rhythm will be concerned also for the healthy office lighting system.

\section{References}

AKSELROD, S., LISHNER, M., Oz, O., BERNHEIM, J., RAVID, M.1987. Spectral Analysis of Fluctuations in Heart Rate: An Objective Evaluation of Autonomic Nervous Control in Chronic Renal Failure. Nephron, 45, 202-206.

BRUCE-LOW, S.S., COTTERRELL, D., JONES, G.E. 2006. Heart Rate Variability During High Ambient Heat Exposure. Space Environ. Med., 77, 915-920.

CHENG, Y., KAWACHI, I., COAKLEY, E. H., SCHWARTZ, J., COLDITZ, G. 2000. Association between Psychosocial Work Characteristics and Health Functioning in American Women: Prospective Study. BMJ, 320, 7247, 1432-1436.

DEMBE, A. E., Erickson, J. B., DELBOS, R. G., BANKS, S.M. 2005. The Impact of Overtime and Long Work Hours on Occupational Injuries and Illnesses: New Evidence from The United States. J Occup. Environ. Med., 62, 9, 588-597.

JORNA, P. G., 1992. Spectral Analysis of Heart Rate and Psychological State: A Review of Its Validity as A Workload Index. Biol. Psychol., 34, 2-3, 237-257.

MALIK, M., Camm, A. J., Bigger, J. T., Breithardt, G., Cerutti, S., Cohen, R. J., Coumel, E. L., Fallen, H. L., Kleiger, R. E., Lombardi, F., Malliani, A., Moss, A.J., Rottman, J.N., Schmidt, G., Schwartz, P.J., Singer, D.H. 1996. Heart Rate Variability: Standards of Measurement, Physiological Interpretation and Clinical Use. Task Force of The European Society of Cardiology and The North American Society Of Pacing And Electrophysiology. Circulation, 93, 5, 1043-1065.

YU, X., ZHANG, J., XIE, D., WANG, J., ZHANG, C. 2009. Relationship between Scalp Potential and Autonomic Nervous Activity During A Mental Arithmetic Task. Auton. Neurosci., 146, 1-2, 81-86. 